\title{
MODIFICATION OF GLUCOMANNAN OF AMORPHOPHALLUS ONCOPHYLLUS AS AN EXCIPIENT FOR IRON ENCAPSULATION PERFORMED USING THE GELATION METHOD
}

\author{
Dyah H. Wardhani ${ }^{凶}$, Nita Aryanti, Fatiha N. Etnanta, Hana N. Ulya \\ Chemical Engineering Department, Faculty of Engineering, Diponegoro University \\ J. Prof. Soedarto SH, Tembalang-Semarang 50277, Indonesia
}

\begin{abstract}
Background. Performing iron fortification by adding the iron compound directly into foods helps to tackle the problem of iron deficiency. However, the fortification brings about some problems as well, including undesirable organoleptic effects, oxidation, and reduced bioavailability. Ensuring appropriate encapsulation can overcome these problems. Hence, it is crucial to identify a proper excipient for protecting the iron. Glucomannan has the potential to be a suitable iron encapsulation excipient. The present work therefore sought to prepare an iron excipient from modified glucomannan using the gelation method. Glucomannan modification was conducted by either chemical reaction or in combination with another compound.

Materials and methods. Glucomannan was isolated from Amorphophallus oncophyllus flour. To maximize encapsulation performance, glucomannan was modified by either deacetylation using $\mathrm{NaOH}(0.4 \mathrm{M})$ or in combination with alginate. After dissolving the excipient (1\%), this solution was mixed with $\mathrm{FeSO}_{4}$ to obtain $25 \mathrm{mg}$ of iron per $1 \mathrm{~g}$ of excipient. The mixture was dropped into either an ethanol or $\mathrm{CaCl}_{2}$ solution for gelation. The beads of seven variations of the resultant glucomannan-based excipient were investigated for their encapsulation efficiency, bead size, and swelling. The release of iron in the two $\mathrm{pH}$ solutions together with their respective release models were also evaluated.

Results. It was revealed that the highest iron efficiency (64\%) was achieved using deacetylated glucomannan, which was gelled in $\mathrm{CaCl}_{2}$. However, this matrix also resulted in the highest release rate in both $\mathrm{pH}$ solutions. The release rate of iron was lower in the low $\mathrm{pH}$ solution $(\mathrm{pH}: 1.2)$ than in the higher $\mathrm{pH}$ solution $(\mathrm{pH}$ : 6.8) for all matrix combinations. The Korsmeyer model was the most fitting model for describing the release profile of iron in both $\mathrm{pH}$ solutions $\left(R^{2} \geq 0.958\right)$ for all excipient variations.

Conclusion. This study suggested the potency of modified glucomannan to be pH-sensitive for iron encapsulation.
\end{abstract}

Keywords: alginate, Amorphophallus oncophyllus, encapsulation, gelation, glucomannan, iron

Funding source declaration. This research was funded by Directorate of Research and Community Service, Directorate General of Higher Education, Ministry of Research, Technology and Higher Education of the Republic of Indonesia through PTUPT Scheme-2017. 


\section{INTRODUCTION}

Iron deficiency is a serious problem that affects the quality of human resources. It is the most prevalent nutritional deficiency in the world, affecting about $29 \%$ of the global population (Gaitán et al., 2012). This deficiency usually results from insufficient dietary iron intake (Davidsson, 2003). Hence, consuming foods rich in dietary iron is an effective way to alleviate iron deficiency. The act of iron fortification, which involves adding an iron compound directly into foods, can cause undesirable organoleptic problems, oxidation, and reduced bioavailability (Schonfeldt and Hall, 2011). One method to overcome this problem is encapsulation. In food systems, the procedure of encapsulation offers several functions such as stability and the protection of sensitive active ingredients from oxygen, water, and light (Nedovic et al., 2011). Encapsulation involves both an active ingredient and a matrix encapsulant and can be performed using a simple gelation method (Thies, 2012). Finding a proper matrix can yield an accomplishment in encapsulating iron.

Glucomannan is a natural neutral polysaccharide that is isolated from the tubers of Amorphophallus sp. This polysaccharide backbone is composed of D-mannose and D-glucose units with $\beta$-1,4-linkage, in which the main chain is $5 \%$ to $10 \%$ acetylated ( $\mathrm{Ji}$ et al., 2017). Its biocompatibility, harmlessness, and biodegradability have attracted extensive attention regarding its potential use as an encapsulant (Yang et al., 2017). Removal of the acetyl groups lead to glucomannan aggregation through hydrogen bonding and formation of a network structure, which results in gel formation (Ji et al., 2017). Hence, glucomannan's properties need to be modified prior to involvement as a matrix in encapsulation using the gelation method. Structurally, replacing the acetyl is conducted through deacetylation using an alkaline such as $\mathrm{NaOH}$ or $\mathrm{KOH}$ (Herranz et al., 2013). Wardhani et al. (2018) reported a positive correlation between deacetylation and iron encapsulation efficiency. Combining glucomannan with other matrix compounds such as alginate and chitosan may increase the efficiency of various active compound encapsulations (Lu et al., 2015; Wang et al., 2014).

Alginate is an unbranched negative charge polysaccharide consisting of 1,4-linked $\beta$-d-mannuronic ( $\mathrm{M}$ residues) and $\beta$-l-guluronic acids ( $\mathrm{G}$ residues) that is commonly isolated from brown algae and bacteria such as Pseudomonas aeruginosa (Tsai et al., 2017). This biopolymer is widely used in both foods and medicines due to its nontoxicity, biocompatibility, biodegradability, and ease of gelation (Zeeb et al., 2015). Research into the encapsulation of iron using a matrix combination containing a glucomannan base has rarely been performed to date. Hence, encapsulation of iron using a glucomannan base was studied in this work. The encapsulation was prepared by way of the gelation method using two different solutions. Physicochemical properties and release of the encapsulated product were observed.

\section{MATERIALS AND METHODS}

\section{Beads preparations}

In this work, seven kinds of matrices were prepared using a glucomannan or alginate base in two gelation solutions, i.e., ethanol and $\mathrm{CaCl}_{2}$ (Table 1). The first matrix (GE) was prepared using $1 \mathrm{~g}$ of glucomannan powder dispersed in $100 \mathrm{~mL}$ of stirred distilled water prior to being mixed with an iron solution $(0.035 \mathrm{~g}$ of $\mathrm{FeSO}_{4} \cdot 7 \mathrm{H}_{2} \mathrm{O}$ in $20 \mathrm{~mL}$ of distilled water) at room temperature. This solution was dropped into ethanol $(150 \mathrm{~mL})$. After $30 \mathrm{~min}$, the beads were collected before drying. The second matrix (AC) was prepared in a manner similar to that of the first one, albeit using

Table 1. Summary of iron bead preparations of various matrices

\begin{tabular}{lll}
\hline $\begin{array}{c}\text { Sample } \\
\text { names }\end{array}$ & \multicolumn{1}{c}{ Matrices } & \multicolumn{1}{c}{$\begin{array}{c}\text { Gelation } \\
\text { solutions }\end{array}$} \\
\hline $\mathrm{GE}$ & glucomannan & ethanol \\
$\mathrm{AC}$ & alginate & $\mathrm{CaCl}_{2}$ \\
DGC & deacetylateed glucomannan & $\mathrm{CaCl}_{2}$ \\
DGAC & $\begin{array}{l}\text { deacetylateed glucomannan } \\
\text { and alginate }\end{array}$ & $\mathrm{CaCl}_{2}$ \\
DGAEC & $\begin{array}{l}\text { deacetylateed glucomannan } \\
\text { and alginate }\end{array}$ & ethanol then $\mathrm{CaCl}_{2}$ \\
DGACE & $\begin{array}{l}\text { deacetylateed glucomannan } \\
\text { and alginate }\end{array}$ & $\mathrm{CaCl}_{2}$ then ethanol \\
GAE & glucomannan alginate & ethanol \\
\hline
\end{tabular}


lone alginate instead of glucomannan dropped into $150 \mathrm{~mL}$ of $\mathrm{CaCl}_{2}(0.2 \mathrm{M})$. In the third matrix (DGC), glucomannan was deacetylated using $\mathrm{NaOH}$ before being used as the encapsulant. One gram of glucomannan was dispersed in stirred $\mathrm{NaOH}$ solution $(0.4 \mathrm{M}$, $100 \mathrm{~mL}$ ) for $60 \mathrm{~min}$ before being mixed with the iron solution. The fourth (DGAC), fifth (DGAEC), and the sixth (DGACE) encapsulants were prepared by mixing $0.5 \mathrm{~g}$ of glucomannan in an $\mathrm{NaOH}$ solution $(0.4 \mathrm{M}$, $50 \mathrm{~mL}$ ) with $0.5 \mathrm{~g}$ of alginate in $50 \mathrm{~mL}$ of distilled water. The seventh matrix (GAE) was prepared using $1.0 \mathrm{~g}$ of glucomannan mixed with alginate of a similar weight, dispersed in $100 \mathrm{~mL}$ of distilled water. Beads of the second, third, and fourth matrices were manufactured by dropping the solution into a $\mathrm{CaCl}_{2}$ solution $(0.2 \mathrm{M}, 150 \mathrm{~mL})$. Beads of the fifth one were dropped in an ethanol solution followed by immersion in the $\mathrm{CaCl}_{2}$ solution. Beads of the sixth one were dropped into two solutions i.e., $150 \mathrm{~mL}$ of $\mathrm{CaCl}_{2}$ and an ethanol solution, in order. Meanwhile, beads of the seventh one were gelated in an ethanol solution. A summary of the bead preparations is presented in Table 1. All of the beads were filtrated to obtain fresh wet beads. After being evaluated for size, the wet beads were oven-dried at $60^{\circ} \mathrm{C}$ for $24 \mathrm{~h}$ prior to undergoing other analyses.

\section{Bead size}

The average diameter of the wet beads $(n)$ was determined as seen in equation (1).

$$
n=\frac{\sum \text { total diameter of the certain bead numbers }}{\text { the certain bead numbers }}
$$

\section{Swelling determination}

Swelling of the beads was determined in two $\mathrm{pH}$ solutions i.e., 1.2 and $6.8(0.1 \mathrm{M}, 100 \mathrm{~mL})$, based on the method of Wardhani et al. (2018). The dried beads $(0.1 \mathrm{~g})$ were diluted in $10 \mathrm{~mL}$ of either a stirred $\mathrm{HCl}$ solution $(0.1 \mathrm{M}, 100 \mathrm{~mL})$ or phosphate-buffered solution $(0.1 \mathrm{M})$ at $37^{\circ} \mathrm{C}$ for $30 \mathrm{~min}$. After centrifugation at $4,000 \mathrm{rpm}$ for $20 \mathrm{~min}$, the remaining paste was used to determine swelling, as follows in equation (2).

$$
\text { Swelling }=\frac{\text { weight of paste }}{\text { weight of dry sample }}
$$

\section{Iron content and encapsulation efficiency}

Dried beads $(0.1 \mathrm{~g})$ were dilluted in an acetic acid solution $(0.1 \mathrm{M}, 50 \mathrm{~mL})$ for $30 \mathrm{~min}$. Ten millilitres of the solution was placed in a $100-\mathrm{mL}$ flask together with $10 \mathrm{~mL}$ of 1,10-phenanthroline and $8.0 \mathrm{~mL}$ of sodium acetate buffer, which was diluted to $100 \mathrm{~mL}$. After 10 minutes of colour development, the absorbance of the mixture solution was read using an ultraviolet-visible spectrophotometer at $508 \mathrm{~nm}$, which represented the native $\mathrm{Fe}^{3+}$ in the sample. Then, $1.0 \mathrm{~mL}$ of hydroxylamine hydrochloride was added to the previous mixture. After $10 \mathrm{~min}$, the absorbance of the mixture was secondly reviewed at $508 \mathrm{~nm}$ for total $\mathrm{Fe}^{3+}$ content, while the absorbance was compared with the iron standard curve.

For this study, the $\mathrm{Fe}^{2+}$ content was the difference between total $\mathrm{Fe}^{3+}$ and the native $\mathrm{Fe}^{3+}$. The encapsulation efficiency was measured based on the amount of unencapsulated $\mathrm{FeSO}_{4}$ available in the gelation solution. The efficiency of encapsulation was calculated using equation (3), as follows.

$$
\mathrm{EE}, \%=\frac{\mathrm{Fe}_{\text {added }}-\mathrm{Fe}_{\text {solution }}}{\mathrm{Fe}_{\text {added }}} \times 100 \%
$$

where:

$$
\begin{aligned}
& \mathrm{EE} \quad \text { - the percent of encapsulation efficiency, } \\
& \mathrm{Fe}_{\text {added }} \text { - the } \mathrm{FeSO}_{4} \text { added in the encapsulation } \\
& \text { process, } \\
& \mathrm{Fe}_{\text {solution }} \text { - the amount of } \mathrm{FeSO}_{4} \text { in the gelation solu- } \\
& \text { tion, respectively. }
\end{aligned}
$$

\section{Iron release and the models}

Nine Erlenmeyers were filled with $50 \mathrm{~mL}$ of either $\mathrm{HCl}$ solution $(0.1 \mathrm{M}, \mathrm{pH} 1.2)$ or phosphate buffer solution ( $\mathrm{pH}$ 6.8). Dried beads ( $0.1 \mathrm{~g})$ were diluted into each solution under $100 \mathrm{rpm}$ orbital stirring. The diluted iron of each Erlenmeyer was determined in a certain time. The concentration of the released iron was modeled using Korsmeyer, Weibull, Hopfenberg, and Gompertz (Dash et al., 2010).

\section{Morphology}

The morphology of the dried beads was observed using a Scanning Electron Microscopy coupled with Energy Dispersive X-ray (SEM/EDX) apparatus (JEOL-JSM $6510 \mathrm{LA})$ at $\times 2,500$ magnification. Prior to SEM analysis, the dry sample was placed on a stub and coated with gold. 


\section{RESULTS AND DISCUSSION}

In this work, seven types of matrices based on glucomannan and/or alginate were used to encapsulate iron using two gelation solutions composed of ethanol and $\mathrm{CaCl}_{2}$, respectively. The wet beads were measured regarding their size, while other analyses such as encapsulation efficiency, controlled release, swelling, and functionality were conducted using the dried beads.

\section{Properties of encapsulated iron}

Encapsulation was conducted using the gelation method or simple coacervation. In this study, ethanol and $\mathrm{CaCl}_{2}$ solutions were selected as media to form the phase separation of a dissolved polysaccharide (Thies, 2012). Figure 1 shows the encapsulation efficiency of iron, fresh bed size, and the percentage of entrapped $\mathrm{Fe}^{2+}$ in various matrices. The matrices that used the $\mathrm{CaCl}_{2}$ solution as gelation agent produced a round bead shape; conversely, ethanol gelation did not yield such a bead shape. Glucomannan is insoluble in ethanol and was expected to form an encapsulant based on phase separation (Wardhani and Cahyono, 2018). Although two phases were formed, they separated as a sol layer instead of as beads. This result could have been due to a weak hydrogen bond between the polysaccharides and the ethanol, which could not trap the water inside the matrix. Hence, these weak and dehydrated beads merged and formed a layer, subsequently.

All of the alginate-base matrices formed beads in the $\mathrm{CaCl}_{2}$ solution (Fig. 2), while GE, DGAEC, and GAE did not. It is well-understood that the negatively charged alginate formed beads upon coming into contact with divalent ions; in this case, it is calcium ions with whom the sodium ions are exchanged with, producing a gel due to chelation of carboxyl groups of the guluronic acid of alginate to the divalent as a central atom, causing the formation of a three-dimensional network, which is known as an egg box model ( $\mathrm{Li}$ et al., 2007). As a crosslinker, the calcium form two bonds, as opposed to sodium, which only forms one bond (Plazinski, 2011) and which could not form complex ones due to charge reason and solubility.

Interestingly, the deacetylated glucomannan (DG) matrix also formed beads in the $\mathrm{CaCl}_{2}$ solution (DGC sample). The DG was glucomannan that reacted with
$\mathrm{NaOH}$ prior to being used for the encapsulant. Reaction with the alkaline replaced the acetyl group of glucomannan, which is responsible for its solubility. Eliminating the acetyl group changed the intramolecular hydrogen bond distribution, inducing a disappearance of the helical structure of glucomannan. This reaction promoted the gelation form of glucomannan (Zhou et al., 2018). Hence, dropping DG into $\mathrm{CaCl}_{2}$ could help in furthering the gelation process and creating more hydrogen bonds. The fact that the bead size was not significantly different suggested that the size was not sensitive to the matrix type. The size and shape of beads are controlled by many factors such as needle diameter, distance between the needle and the surface of gelation solution, matrix concentration solution, and viscosity and surface tension (Klokk and Melvik, 2002). This study used a viscosity similar to that of polysaccharides, since the total concentration of the matrix was set as the same. Moreover, all samples used the same diameter of the needle for dropping the beads. Hence, the fresh beads of various matrices are relatively similar in terms of diameter size.

Efficiency is one of the parameters that can suggest successful encapsulation. The efficiency of encapsulation was determined using the dried beads and ranged ultimately from $17.43 \%$ to $64.73 \%$. The highest encapsulation efficiency was produced by DGC encapsulation, followed by with glucomannan in ethanol (GE sample). The presence of alginate reduced the efficiency. It was reported that the alginate gel is porous (Sergeeva et al., 2015), which could play a role in rereleasing the trapped iron, reducing the efficiency. Increasing the glucomannan gelation process by dropping into $\mathrm{CaCl}_{2}$ has helped in bonding more iron. Since the concentration of the total matrix was maintained similarly to other samples, the addition of alginate into glucomannan reduced the ability of the matrix to trap the iron, as explained previously. Figure 1 also shows an unspecific pattern of entrapped $\mathrm{Fe}^{2+}$ in various matrices. Ethanol seems to help in protecting iron from oxidation due to the insolubility of $\mathrm{FeSO}_{4}$. Further studies are needed that explore the capability of the matrices to inhibit this oxidation.

All of the beads of various matrices showed a roundoval shape (Fig. 2). More specifically, the AC matrix produced end-tail beads. This could be due to a fastoccurring gelation of alginate upon being dropped into 


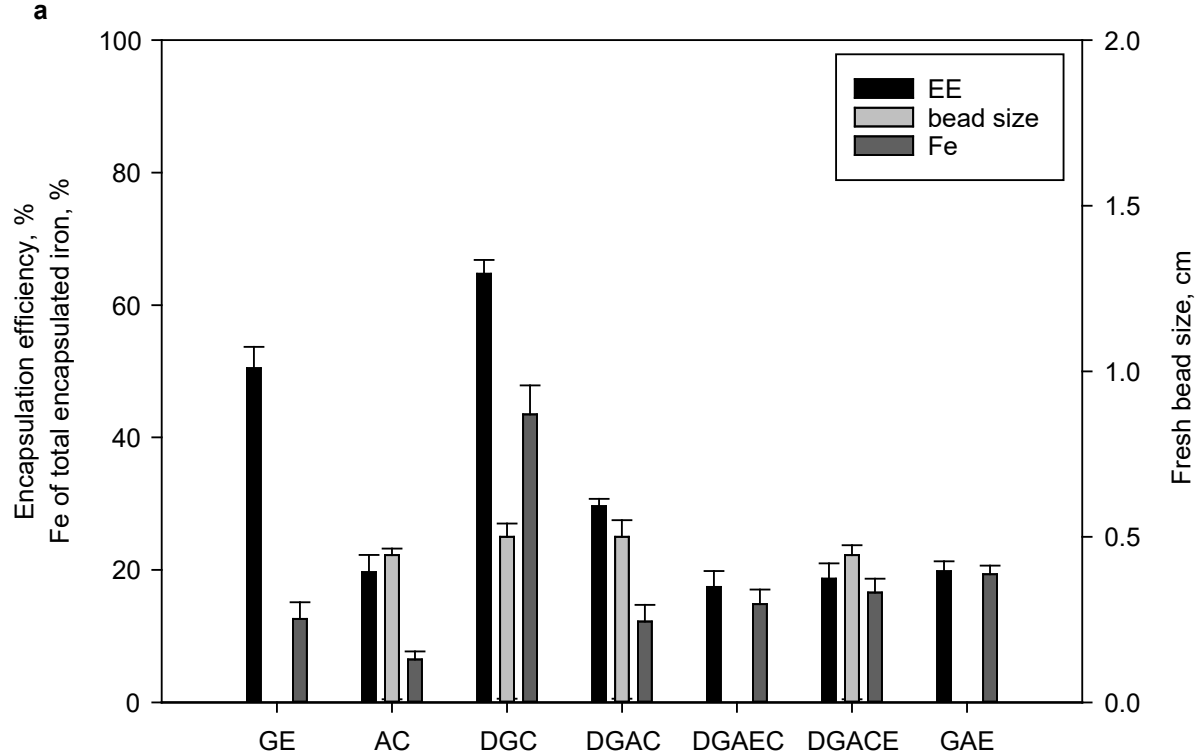

b

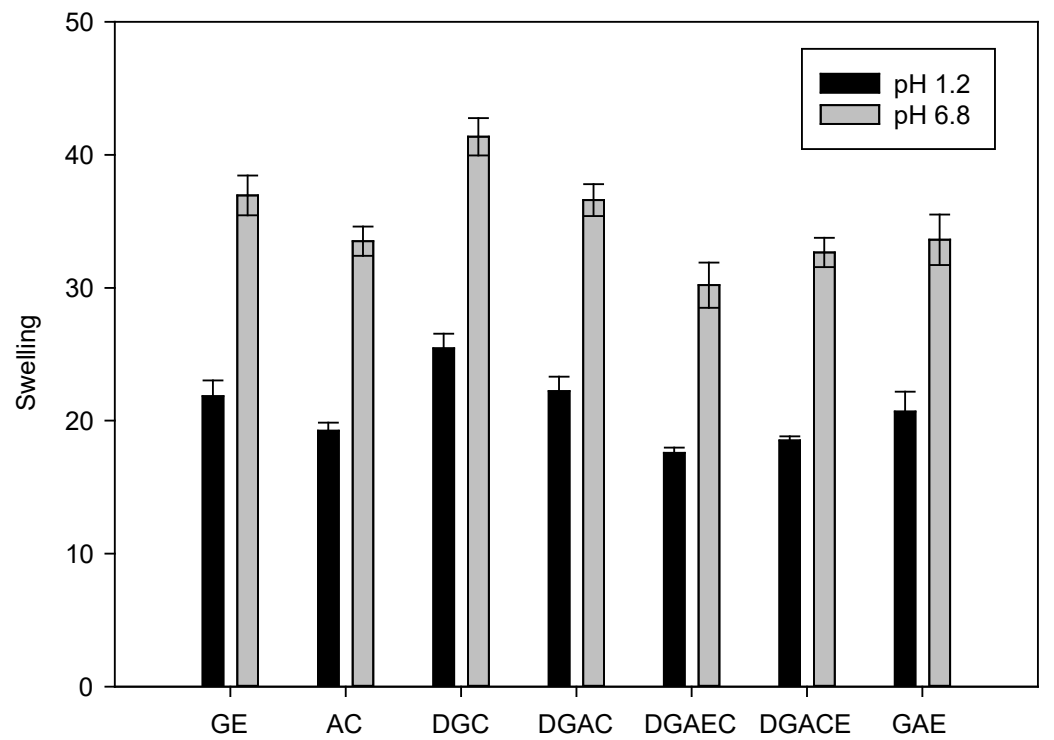

Fig. 1. Properties of encapsulated iron using various matrices: a - encapsulation efficiency, bead size, and percentage of $\mathrm{Fe}^{2+}$ over total entrapped iron, $\mathrm{b}-$ swelling at $\mathrm{pH} 1.2$ and 6.8; $\mathrm{GE}$ - glucomannan in ethanol, $\mathrm{AC}$ - alginate in $\mathrm{CaCl}_{2}$, DGC - deacetylated glucomannan in $\mathrm{CaCl}_{2}, \mathrm{DGAC}$ - combination of deacetylated glucomannan and alginate in $\mathrm{CaCl}_{2}$, DGAEC - combination of deacetylated glucomannan and alginate in ethanol and subsequently dropped in $\mathrm{CaCl}_{2}$, DGACE - combination of deacetylated glucomannan and alginate in $\mathrm{CaCl}_{2}$ and subsequently dropped in ethanol, GAE - combination of glucomannan and alginate in ethanol. Data - average of three replicates 


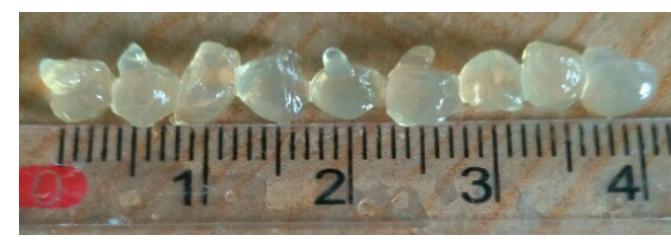

a

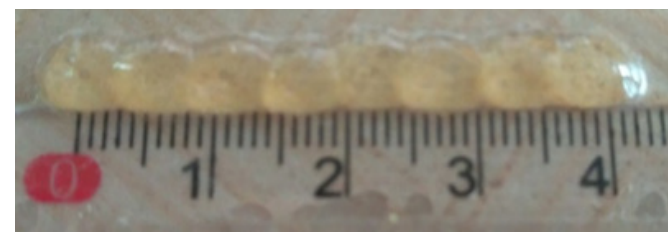

c

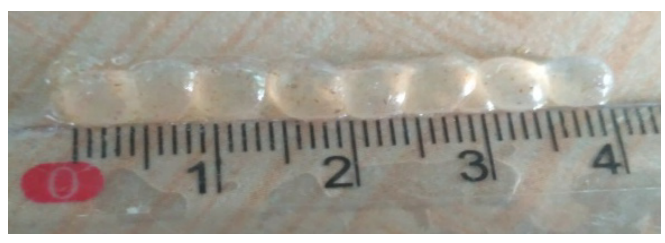

b

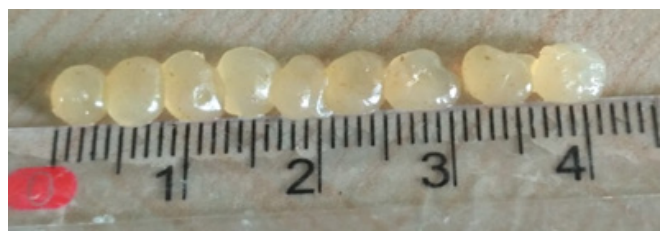

d

Fig. 2. Iron beads from various matrices: a - alginate with $\mathrm{CaCl}_{2}$ gelling agent $(\mathrm{AC}), \mathrm{b}$ - deacetylated glucomannan with $\mathrm{CaCl}_{2}$ gelling agent (DGC), $\mathrm{c}-$ a mixture of deacetylated glucomannan and alginate with $\mathrm{CaCl}_{2}$ gelling agent (DGAC), $\mathrm{d}-\mathrm{a}$ mixture of deacetylated glucomannan and alginate with $\mathrm{CaCl}_{2}$ and ethanol gelling agent (DGACE)

the $\mathrm{CaCl}_{2}$ solution. $\mathrm{CaCl}_{2}$ was reported as one of the most frequently used solutions in cross-linking alginate that leads to rapid gelation (Lee and Mooney, 2012). All of the resulting beads were strong and firm except for those of DGC, which did not contain alginate. The present results suggest that alginate could have contributed to the firmness of the beads. It was reported that the guluronate of alginate leads to forming strong and firm gels (Alihosseini, 2016).

\section{Iron release}

The profiles of iron release from various matrices at the two pHs are presented in Figure 3. Initially, the release rose in the first five minutes followed by with the lower release rate. The same sequence of release rate was observed in both $\mathrm{pHs}$, in which the fastest release was seen with DGC, and the slowest one was seen with DGACE. Interestingly, the sequence of release rate was in line with the efficiency and swelling. High efficiency indicates that the beads contain high iron concentrations, which could interrupt the internal matrix bonds that trapped the iron. As a result, a high release rate was observed in the high-efficiency encapsulatio one. The iron release rates with the double gelation samples (DGACE and DGAEC) were the lowest in both pHs. This finding suggests that, although both gelations produced a matrix type of encapsulation, in which the iron was distributed either inside or on the surface of the beads, these double encapsulations helped in reducing the release of iron. The double gelation may also contribute in limiting swelling ability, hence suppressing the release of iron.

Separately, the release rate at $\mathrm{pH} 1.2$ was lower than that seen at $\mathrm{pH} 6.8$, in which both $\mathrm{pHs}$ showed typically two stages of release. Burst release was observed in the first stage, which was attributed to the migration of water into the matrix driven by the osmotic pressure. Partial dissolution of the active compound could be responsible for the burst release (Nedovic et al., 2011).

Figures 1 and 3 present a positive relation of the release with the swelling sequences. This result is supported by Wang et al. (2014), who reported a lower degree of swelling of glucomannan at $\mathrm{pH} 1.2$ than at $\mathrm{pH}$ 6.8. Swelling and release are affected by hydrogen bonds and electrostatic interactions among the functional groups in solution $\mathrm{pH}$ conditions as well as the osmotic balance pressure between the internal and external mediums of the hydrogel network (Lu et al., 2015). Moreover, alginate gel also is a $\mathrm{pH}$-sensitive 

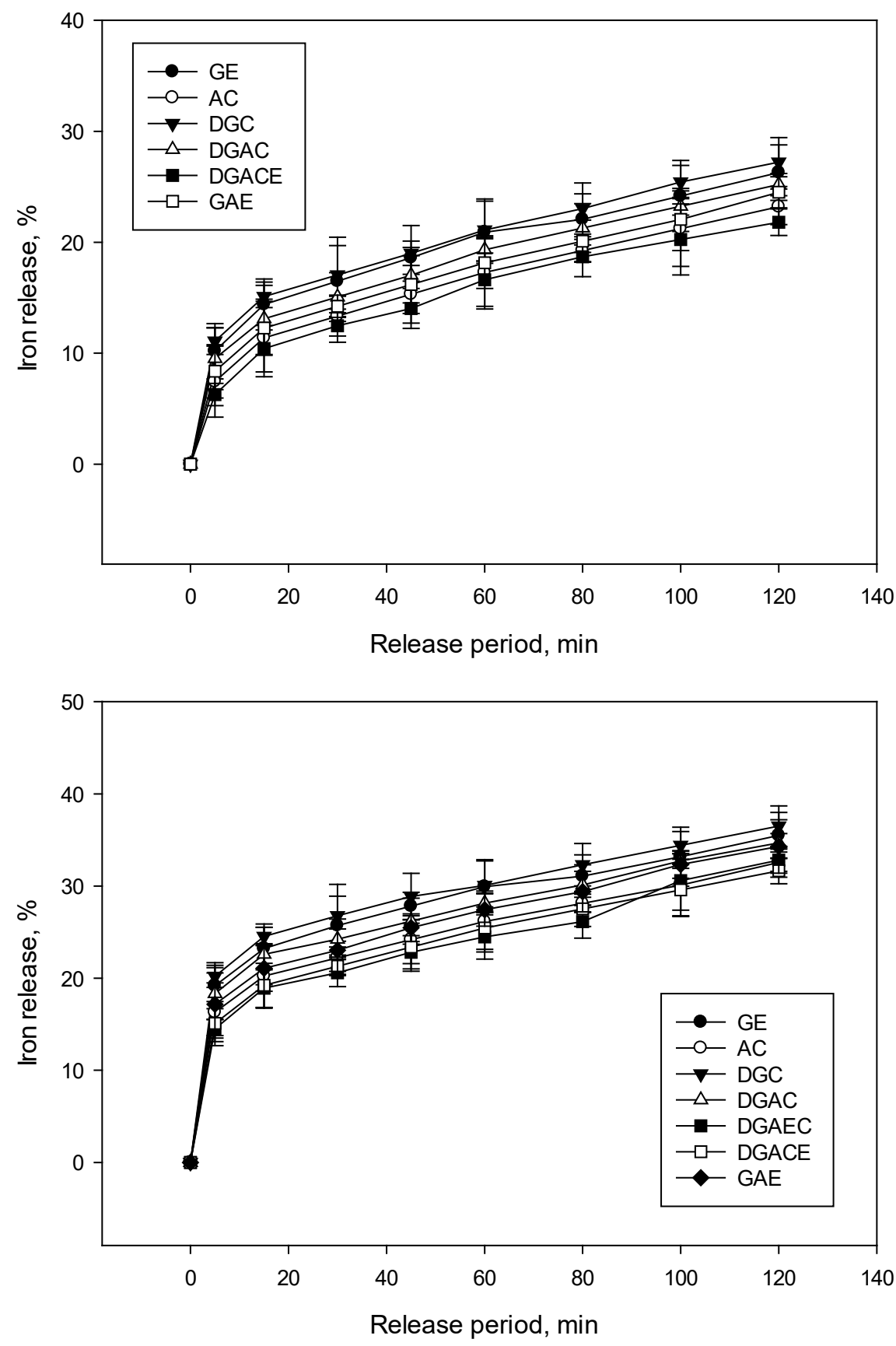

Fig. 3. Profile release of iron from various matrices at $\mathrm{pH} 1.2$ of $\mathrm{HCl}$ solution (top) and at $\mathrm{pH} 6.8$ of phosphate buffer (bottom): GE - glucomannan in ethanol, AC - alginate in $\mathrm{CaCl}_{2}$, DGC - deacetylated glucomannan in $\mathrm{CaCl}_{2}$, DGAC - combination of deacetylated glucomannan and alginate in $\mathrm{CaCl}_{2}$, DGAEC - combination of deacetylated glucomannan and alginate in ethanol and subsequently dropped in $\mathrm{CaCl}_{2}, \mathrm{DGACE}-\mathrm{com}-$ bination of deacetylated glucomannan and alginate in $\mathrm{CaCl}_{2}$ and subsequently dropped in ethanol, GAE - combination of glucomannan and alginate in ethanol. Data - average of three replicates 
Wardhani, D. H., Aryanti, N., Etnanta, F. N., Ulya, H. N. (2019). Modification of glucomannan of Amorphophallus oncophyllus as an excipient for iron encapsulation performed using the gelation method. Acta Sci. Pol. Technol. Aliment., 18(2), $173-184$. http://dx.doi.org/10.17306/J.AFS.2019.0651

Table 2. Constants and coefficient of determination of iron release models of various encapsulants

\begin{tabular}{|c|c|c|c|c|c|c|c|c|c|c|c|c|}
\hline \multirow{2}{*}{ Variable } & \multicolumn{3}{|c|}{ Korsmeyer } & \multicolumn{3}{|c|}{ Weibull } & \multicolumn{3}{|c|}{ Hopfenberg } & \multicolumn{3}{|c|}{ Gompertz } \\
\hline & $n$ & $a$ & $R^{2 \mathrm{~h}}$ & $a$ & $b$ & $R^{2}$ & ko & $n$ & $R^{2}$ & $\alpha$ & $\beta$ & $R^{2}$ \\
\hline \multicolumn{13}{|l|}{ pH 1.2} \\
\hline GE & 0.287 & 0.064 & 0.993 & 15.631 & 0.316 & 0.991 & -0.007 & -0.031 & 0.948 & 0.979 & -0.373 & 0.979 \\
\hline $\mathrm{AC}$ & 0.346 & 0.042 & 0.993 & 23.768 & 0.373 & 0.991 & -0.008 & -0.029 & 0.937 & 0.977 & -0.402 & 0.977 \\
\hline DGC & 0.274 & 0.069 & 0.986 & 14.256 & 0.303 & 0.983 & -0.006 & -0.031 & 0.928 & 0.065 & -0.367 & 0.965 \\
\hline DGAC & 0.303 & 0.057 & 0.987 & 17.581 & 0.328 & 0.984 & -0.007 & -0.030 & 0.926 & 0.966 & -0.377 & 0.966 \\
\hline DGAEC & 0.415 & 0.029 & 0.994 & 34.673 & 0.437 & 0.993 & -0.009 & -0.029 & 0.934 & 0.982 & -0.441 & 0.982 \\
\hline DGACE & 0.383 & 0.034 & 0.992 & 29.444 & 0.413 & 0.992 & -0.009 & -0.029 & 0.946 & 0.982 & -0.429 & 0.984 \\
\hline GAE & 0.324 & 0.049 & 0.990 & 20.511 & 0.352 & 0.987 & -0.008 & -0.030 & 0.926 & 0.97 & -0.391 & 0.970 \\
\hline \multicolumn{13}{|l|}{ pH 6.8} \\
\hline GE & 0.186 & 0.137 & 0.988 & 6.389 & 0.218 & 0.984 & -0.004 & -0.035 & 0.947 & 0.969 & -0.322 & 0.969 \\
\hline $\mathrm{AC}$ & 0.208 & 0.113 & 0.979 & 8.531 & 0.239 & 0.974 & -0.005 & -0.033 & 0.924 & 0.954 & -0.33 & 0.954 \\
\hline DGC & 0.177 & 0.149 & 0.984 & 6.338 & 0.209 & 0.979 & -0.004 & -0.035 & 0.940 & 0.963 & -0.317 & 0.963 \\
\hline DGAC & 0.191 & 0.131 & 0.971 & 7.294 & 0.223 & 0.966 & -0.004 & -0.034 & 0.916 & 0.945 & 0.324 & 0.945 \\
\hline DGAEC & 0.241 & 0.095 & 0.958 & 10.351 & 0.274 & 0.950 & -0.006 & -0.036 & 0.874 & 0.920 & -0.369 & 0.920 \\
\hline DGACE & 0.226 & 0.102 & 0.985 & 9.549 & 0.257 & 0.981 & -0.005 & -0.034 & 0.933 & 0.963 & 0.347 & 0.963 \\
\hline $\mathrm{GAE}^{\mathrm{g}}$ & 0.211 & 0.118 & 0.973 & 8.241 & 0.245 & 0.967 & -0.005 & -0.036 & 0.913 & 0.945 & -0.348 & 0.945 \\
\hline
\end{tabular}

$\mathrm{GE}$ - glucomannan in ethanol, $\mathrm{AC}$ - alginate in $\mathrm{CaCl}_{2}, \mathrm{DGC}$ - deacetylated glucomannan in $\mathrm{CaCl}_{2}$, DGAC - combination of deacetylated glucomannan and alginate in $\mathrm{CaCl}_{2}, \mathrm{DGAEC}$ - combination of deacetylated glucomannan and alginate in ethanol and subsequently dropped in $\mathrm{CaCl}_{2}, \mathrm{DGACE}$ - combination of deacetylated glucomannan and alginate in $\mathrm{CaCl}_{2}$ and subsequently dropped in ethanol, GAE - combination of glucomannan and alginate in ethanol.

In bold - the highest $R^{2}$ compared to other models for the same matrix.

polymer that shrinks in acidic conditions and swells in high-pH environments, respectively (Tsai et al., 2017).

The combination of glucomannan with alginate reduced the release and swelling of the encapsulant in $\mathrm{pH}$ 1.2. In this $\mathrm{pH}$, the carboxylic groups of alginates could form a strong hydrogen bond, which resists water penetration (Wang et al., 2014). Meanwhile, the phosphate buffer with a $\mathrm{pH}$ of 6.8 in this study was prepared using monosodium phosphate and disodium phosphate. The sodium ions could replace the $\mathrm{Ca}^{2+}$ of $\mathrm{CaCl}_{2}$, which linked to carboxylic groups of alginate. This replacement of a bivalent with a monovalent ion caused the breakup of the bond between $\mathrm{Ca}^{2+}$ and two polyuronate chains known as the "egg box" structure (Plazinski, 2011). This breakup resulted in a greater distance between the polymeric chains and allowed the fluid to fill up. Hence, the swelling of the matrix at $\mathrm{pH} 6.8$ was higher than that at with a more acidic of the release solutions.

The release was modeled to predict release phenomena using four models, i.e., Korsmeyer, Weibull, Hopenberg, and Gompertz. The accuracy of the model was justified by the coefficient of determination $\left(R^{2}\right)$ of an individual model. The acceptable correlation was achieved when $R^{2}$ values were equal to 0.970 or higher (Balcerzak and Mucha, 2010). The constants of the 

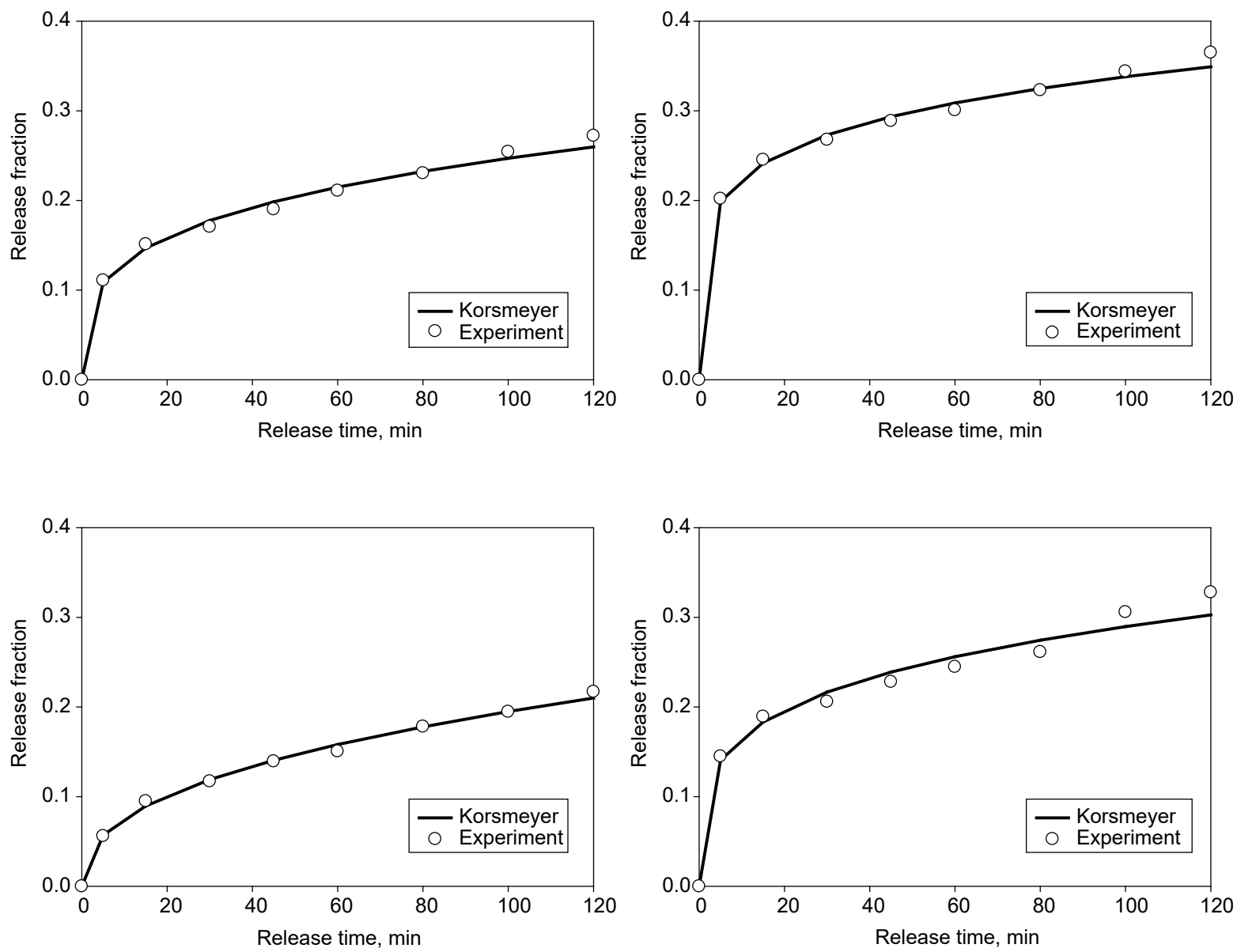

Fig. 3. Release profile of iron from DGC (top) and DGAEC (bottom) matrices at pH 1.2 (left) and pH 6.8 (right) using Korsmeyer and Hopernberg model: DGC - deacetylated glucomannan into $\mathrm{CaCl}_{2}$, DGAEC - combination of deacetylated glucomannan and alginate in ethanol and subsequently dropped into $\mathrm{CaCl}_{2}$

fitted models as well as the $R^{2}$ are presented in Table 2 for release at $\mathrm{pH} 1.2$ and $\mathrm{pH} 6.8$. The Korsmeyer model was superior for describing the released iron profile of all excipient variations in both $\mathrm{pHs}$ as opposed to other models. The $R^{2}$ values of the Korsmeyer model were $\geq 0.958$.

Considering the $n$ value of the Korsmeyer model, which was less than 0.45 (Table 2), it was proposed that the mechanism of iron release from the matrix followed Fickian diffusion with $t^{0.5}$ of rate as a function of time (Dash et al., 2010). This indicated that the diffusion of active compounds plays a major role as compared with encapsulant degradation (Lu et al., 2015). Moreover, this model suggested some processes occurred simultaneously including diffusion of water into the beads, followed with swelling of the beads as water entered the matrix (Korkiatithaweechai et al., 2011). The similar pattern seen between the release (Fig. 3) and bead swelling (Fig. 1) supported this idea. Plotting of the Korsmeyer release model at the highest $R^{2}$ values of the DGC and DGAEC matrices is presented in Figure 3.

\section{Morphology}

Figure 4 represents the morphology of dried beads of encapsulated iron of DGC and DGAC. More crumb particles were observed adhered on the surface of DGC than on that of DGAC. It is suggested that the 
Wardhani, D. H., Aryanti, N., Etnanta, F. N., Ulya, H. N. (2019). Modification of glucomannan of Amorphophallus oncophyllus as an excipient for iron encapsulation performed using the gelation method. Acta Sci. Pol. Technol. Aliment., 18(2), $173-184$. http://dx.doi.org/10.17306/J.AFS.2019.0651
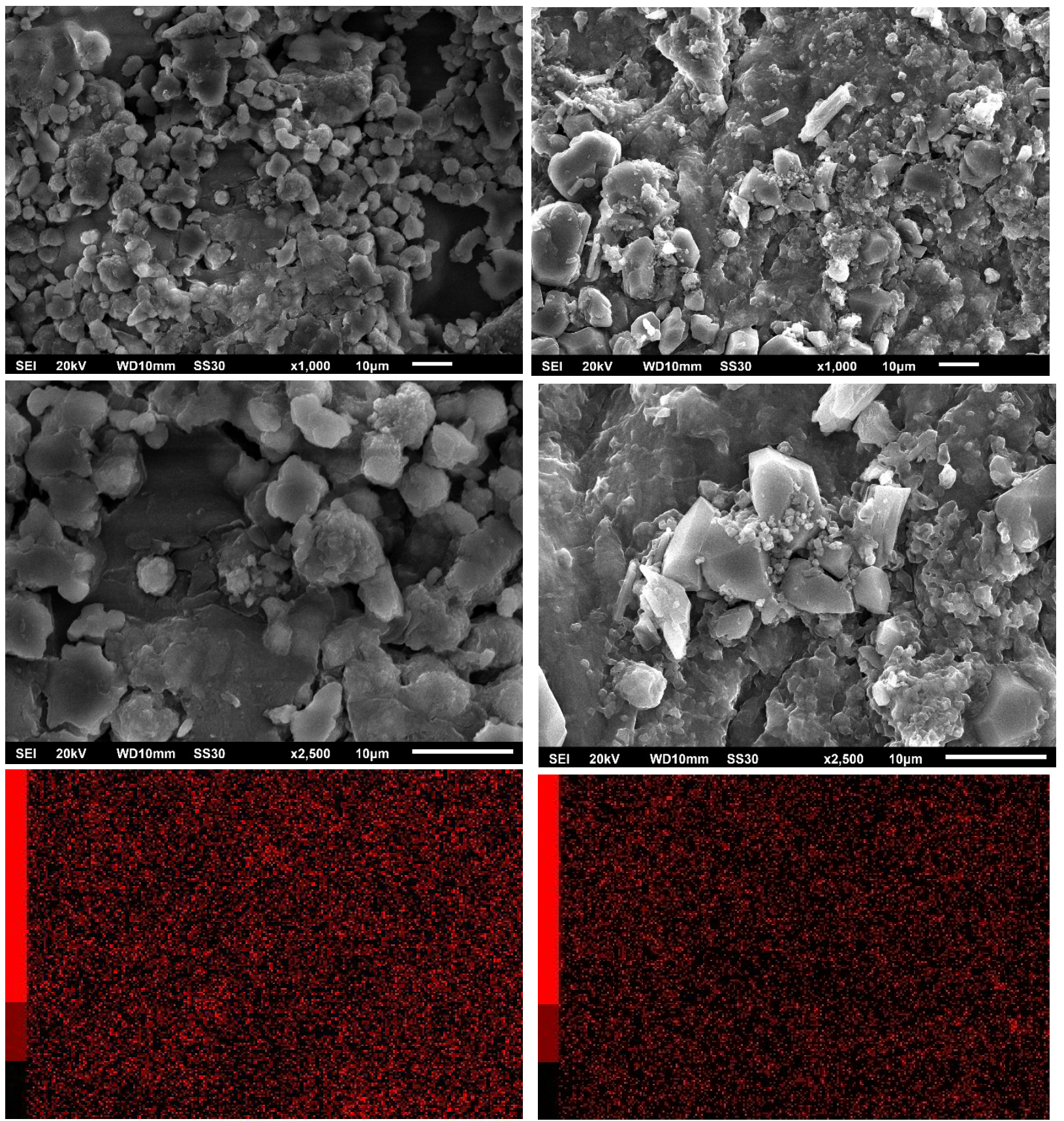

\section{$20 \mu \mathrm{m}$}

Fe K

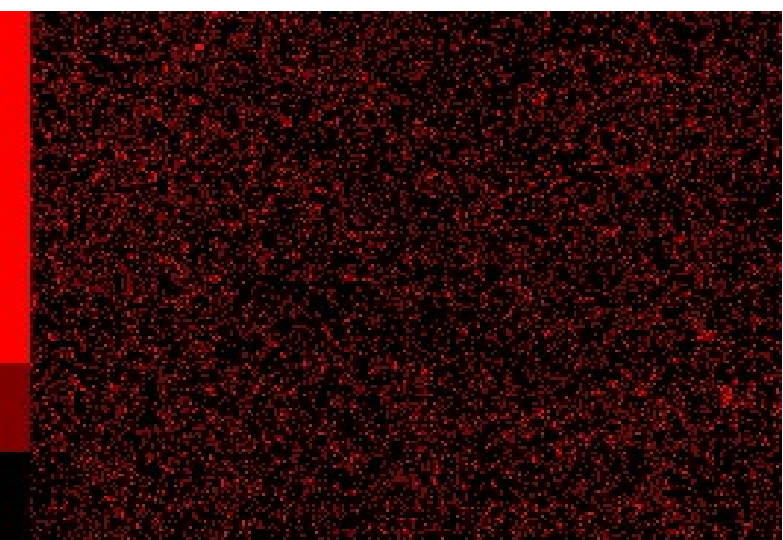

$20 \mu \mathrm{m}$

Fe K

Fig. 4. SEM $(\times 1,000$-top and $\times 2,500$-middle) and EDX mapping with $\times 2,500$ magnification (bottom) of iron encapsulation using DGC (left) and DGAC (right) matrices. Red colour of EDX mapping is represented entrapped iron in the matrix 
crumbs could be the encapsulated iron. Moreover, the EDX mapping shows a higher intensity of red dots, representing more entrapped iron on DGC than on DGAC. This description is supported by the efficiency results of Figure 1.

\section{CONCLUSION}

Glucomannan modifications influenced the properties and ability of encapsulated iron. The composition of the matrix did not affect the bead size significantly. The highest iron encapsulation efficiency (64.73\%) was produced by the matrix prepared with DG, which was dropped in $\mathrm{CaCl}_{2}$. However, this matrix resulted in the highest release rate in both $\mathrm{pHs}$. The release rate of iron was lower in the $\mathrm{pH} 1.2$ solution than in the $\mathrm{pH} 6.8$ solution for all matrix combinations. The Korsmeyer model was the most suitable model for describing the release profile of iron $\left(R^{2}>0.958\right)$ in both $\mathrm{pHs}$. This research showed that a glucomannan matrix has a potential as a $\mathrm{pH}$-sensitive option for iron encapsulation.

\section{ACKNOWLEDGEMENTS}

The financial support of Directorate of Research and Community Service, Directorate General of Higher Education, Ministry of Research, Technology and Higher Education of the Republic of Indonesia through PTUPT Scheme-2017 is gratefully acknowledged.

\section{REFERENCES}

Alihosseini, F. (2016). Plant-based compounds for antimicrobial textiles. In G. Sun (Ed.), Antimicrobial textiles. Plant-based compounds for antimicrobial textiles (pp. 155-195). Woodhead Publishing.

Balcerzak, J., Mucha, M. (2010). Analysis of model drug release kinetics from complex matrices of polylactide-chitosan. Progr. Chem. Appl. Chitin Deriv., 15, 117-126.

Dash, S., Murthy, P. N., Nath, L., Chowdhury, P. (2010). Kinetic modeling on drug release from controlled drug delivery systems. Acta Pol. Pharm. Drug Res., 67(3), 217-223.

Daemi, H., Barikani, M. (2012). Synthesis and characterization of calcium alginate nanoparticles, sodium homopolymannuronate salt and its calcium nanoparticles. Sci. Iran., 19(6), 2023-2028.

Davidsson, L. (2003). Approaches to improve iron bioavailability from complementary foods. J. Nutr., 3, $1560 \mathrm{~S}-1562 \mathrm{~S}$.

Gaitán, D., Olivares, M., Lönnerdal, B., Brito, A., Pizarro, F. (2012). Non-heme iron as ferrous sulfate does not interact with heme iron absorption in humans. Biol. Trace Elem. Res., 150(1-3), 68-73.

Herranz, B., Tovar, C. A., Solo-de-Zaldívar, B., Borderias, A. J. (2013). Influence of alkali and temperature on glucomannan gels at high concentration. LWT - Food Sci. Technol., 51(2), 500-506.

Ji, L., Xue, Y., Feng, D., Li, Z., Xue, C. (2017). Morphology and gelation properties of konjac glucomannan: effect of microwave processing. Int. J. Food Prop., 20(12), 3023-3032.

Klokk, T. I., Melvik, J. E. (2002). Controling the size of alginate gel beads by use of a high electrostatic potential. J. Microencaps., 19(4), 415-424.

Korkiatithaweechai, S., Umsarika, P., Praphairaksit, N., Muangsin, N. (2011). Controlled release of diclofenac from matrix polymer of chitosan and oxidized konjac glucomannan. Marine Drugs, 9, 1649-1663.

Lee, K. Y., Mooney, D. J. (2012). Alginate: properties and biomedical applications. Progr. Polymer Sci., 37, 106-126.

Li, L., Fang, Y., Vreeker, R., Appelqvist, I. (2007). Reexamining the egg-box model in calcium-alginate gels with X-ray diffraction. Biomacromolecules, 8, 464-468.

Lu, M., Li, Z., Liang, H., Shi, M., Zhaom L., Li, W., Chen, Y., ..., Li, Y. (2015). Controlled release of anthocyanins from oxidized konjac glucomannan microspheres stabilized by chitosan oligosaccharides. Food Hydrocoll., 51, 476-485.

Lu, J., Wang, L., Li, Y., Hu, D., Zhao, Y. (2015). Synthesis and properties of $\mathrm{pH}$-, thermos- and salt-sensitive modified poly (aspartic acid)/poly (vinyl alcohol) IPN hydrogel and its drug-controlled release. BioMed Res. Int., 236745, 1-12.

Nedovic, V., Kalusevic, A., Manojlovic, V., Levic, S., Bugarski, B. (2011). An overview of encapsulation technologies for food applications. Procedia Food Sci., 1, 1806-1815.

Plazinski, W. (2011). Molecular basis of calcium binding by polyguluronate chains. Revising the egg-box model. J. Computat. Chem., 32(4), 2988-2995.

Ramteke, K. H., Dighe, P. A., Kharat, A. R., Patil, S. V. (2014). Mathematical models of drug dissolution: a review. Scholars Acad. J. Pharm., 3(5), 388-96. 
Schonfeldt, H. C., Hall, N. G. (2011). Determining iron bioavailability with a constant heme iron value. J. Food Comp. Anal., 24(4-5), 738-740.

Sergeeva, A. S., Gorin, D. A., Volodkin, D. V. (2015). In-situ assembly of Ca-alginate gels with controlled pore loading/ release capability. Langmuir, 31, 10813-10821.

Singhvi, G., Singh, M. (2011). Review: in-vitro drug release characterization models. Int. J. Pharm. Stud. Res., E, 2(1), 77-84.

Thies, C. (2012). Microencapsulation methods based on biopolymer phase separation and gelation phenomena in aqueous media. In N. Garti, D. J. McClements (Eds.), Encapsulation technologies and delivery systems for food ingredients and nutraceuticals $\left(1^{\text {st }}\right.$ ed., pp. 177207). Woodhead Publishing.

Tsai, F.-H., Kitamura, Y., Kokawa, M. (2017). Effect of gum arabic-modified alginate on physicochemical properties, release kinetics, and storage stability of liquid-core hydrogel beads. Carbohydr. Polym., 174, 1069-1077.

Wang, J., Liu, C., Shuaic, Y., Cui, X., Nie, L. (2014). Controlled release of anticancer drug using graphene oxide as a drug-binding effector in konjac glucomannan/sodium alginate hydrogels. Colloids and Surfaces B: Biointerfaces, 113, 223-229.

Wardhani, D. H., Cahyono, H., Dwinanda, M. F. H., Nabila, P. R., Aryanti, A., Pangestuti, D. R. (2018). Performance of deacetyled glucomannan as iron encapsulation excipient. MATEC Web of Conferences, 156, 01021.
Wardhani, D. H., Nugroho, F., Muslihudin, M., Aryanti, N. (2016). Application of response surface method on purification of glucomannan from Amorphophallus oncophyllus by using 2-propanol. Sci. Study Res. Chem. Chemic. Eng. Biotechnol. Food Ind., 17(1), 063-074.

Wardhani, D. H., Cahyono, H. (2018). The effect of alcohol on bead performance of encapsulated iron using deacetylated glucomannan. MATEC Web of Conferences, $156,01005$.

Wardhani, D. H., Hapsari, F. D., Suryana, K. M., Aryanti, N., Cahyono, H. (2018). Physicochemical properties of glucomannan-alginate as vitamin $\mathrm{C}$ excipient. EVERGREEN Joint J. Novel Carbon Res. Sci. Green Asia Strat., 5(2), 6-10.

Yang, D., Yuan, Y., Wang, L., Wang, X., Mu, R., Pang, J., Xiao, J., Zheng, Y. (2017). A review on konjac glucomannan gels: microstructure and application. Int. J. Molec. Sci., 18, 2250-2267.

Zeeb, B., Saberi, A. H., Weiss, J., McClements, D. J. (2015). Formation and characterization of filled hydrogel beads based on calcium alginate: factors influencing nanoemulsion retention and release. Food Hydrocoll., 50, 27-36.

Zhou, Y., Jiang, R., Perkins, W. S., Cheng, Y. (2018). Morphology evolution and gelation mechanism of alkali induced konjac glucomannan hydrogel. Food Chem., 269, $80-88$. 